\title{
GIANT PLACENTAL CHORIOANGIOMA WITH AN UNEVENTFUL CLINICAL COURSE
}

\author{
F. Limaiem ${ }^{1}$, Anissa Ben amor ${ }^{2}$, Khalil Saffar ${ }^{3}$, Ahmed Halouani $^{2}$, and saadia bouraoui ${ }^{1}$ \\ ${ }^{1}$ Centre Hospitalier Universitaire Mongi Slim \\ ${ }^{2}$ University Hospital Center Mongi Slim \\ ${ }^{3}$ University of Tunis El Manar
}

March 27, 2021

\begin{abstract}
A 33-year-old primiparous woman presented with reduced fetal movements during the gestational age of 33 weeks. Ultrasonography showed a heterogeneous and hypoechoic placental lesion measuring $8 \mathrm{~cm}$. A week later, the patient delivered a live healthy male neonate. Histological examination of the placental mass established the diagnosis of placental chorioangioma.
\end{abstract}

\section{INTRODUCTION}

Initially described by Clarke in 1798 , placental chorioangiomas are benign non-trophoblastic, vascular neoplasms of the placenta [1]. Their true incidence is unknown since the majority of them are small, clinically asymptomatic and may be missed during obstetric screening procedures. Large chorioangiomas $(>5 \mathrm{~cm})$ are rarer and are often associated with an increased risk of pregnancy complications [2]. Herein, we report a peculiar case of a giant placental chorioangioma without significant feto-maternal complications except for prematurity.

\section{CLINICAL HISTORY}

A 33-year-old primigravida woman with a past medical history of thyroidectomy, presented to the outpatient gynecology clinic during the gestational age of 33 weeks, complaining of reduced fetal movements. Physical examination revealed a uterine fundal height of $29 \mathrm{~cm}$ appropriate for the gestational age. Ultrasonography showed a single live fetus of 32-33 weeks in breech presentation and an anterior fundal placenta. A welldefined heterogeneous and hypoechoic space-occupying lesion measuring $8.3 \times 4.9 \mathrm{~cm}$ noted in the placenta bulging into amniotic cavity at the site of umbilical cord insertion was interpreted as consistent with a chorioangioma (Figure 1A \& 1B). Neither fetal cardiomegaly nor early signs of hydrops fetalis were noted. Non stress tests revealed no sign of fetal distress. Spontaneous labor commenced at 34 weeks of gestation and she delivered a live male baby with a breech presentation via a cesarean delivery with an Apgar score of 9 in the first minute and 10 in the fifth minute. The newborn weighed $2.7 \mathrm{~kg}$ and did not show any signs of anemia $(\mathrm{Hb}: 19 \mathrm{~g} / \mathrm{dl})$ or distress. The placenta was sent to the pathology department for histological examination. Grossly, the delivered placenta measured $16 \times 15 \times 3 \mathrm{~cm}$ and weighed $835 \mathrm{~g}$. There was a welldefined lobular mass on the fetal surface measuring $8 \times 4.9 \mathrm{~cm}$ and located near the insertion of the umbilical cord (Figure $1 \mathrm{C}$ ). The length of the umbilical cord was $40 \mathrm{~cm}$. On serial sections, the cut surface of the mass was solid whitish with few reddish and micro cystic areas (Figure $1 \mathrm{D}$ ). The rest of the placenta, membranes, and umbilical cord were unremarkable. The placenta was intact and complete, and the outer surface of the mass was congested with prominent vascular markings. Microscopic examination of the placental mass showed a well-demarcated lesion composed of numerous capillary sized vascular channels set in a fibroid matrix. Sections from the umbilical cord were unremarkable. The histology results, therefore, confirmed the 
diagnosis of a chorioangioma of capillary type (Figures 2A, 2B, 2C). Immunohistochemical study showed strong positive immunostaining of endothelial cells for CD 34 (Figure 2D). The infant did not have anemia and hypoproteinemia and there was no evidence of hydrops fetalis at birth. The mother and her baby were discharged on the fifth day post-delivery after the newborn was found to be normal on subsequent examinations.

\section{DISCUSSION}

Also called " chorangioma placentae", placental chorioangioma is the most frequent non-trophoblastic tumor of the placenta which originates from the placental chorionic mesenchyme [3]. Placental chorioangioma accounts for approximately $1 \%$ of pregnancies and is predominant in Caucasian women [4]. The majority of researchers consider chorioangioma to be a malformation rather than a true neoplasm [4]. Some environmental factors, namely hypoxic stimulus, high altitude, and vascular growth factors, are possible associations with this tumor's occurrence [5]. Large chorioangiomas can induce several complications in pregnancy such as polyhydramnios, premature labor, placenta previa, and premature placental separation, leading to high perinatal morbidity and mortality [6,7]. Other complications of large chorioangiomas include placental functional inadequacy, mechanical obstruction of the blood flow, and increased vascular surface area. This induces increased transudation of fluid, resulting in polyhydramnios [8]. The pathological complications seen in the neonates include thrombocytopenia, anemia, stillbirth, edema, non-immune hydrops fetalis, prematurity, intrauterine growth retardation, or fetal death. Arteriovenous shunts in large chorioangiomas cause impairment of the fetal circulation. $[9,10]$. In the present case, the pregnancy of this 33-year-old primiparous woman with a large placental chorioangioma had prematurity as the only adverse effect. Prematurity was probably the result of the large volume of the placental chorangioma occupying a significant amount of intrauterine volume and therefore leading to the induction of early uterine contractions that culminated in the premature delivery. On ultrasonography, chorioangiomas are well-circumscribed hypoechoic masses that often protrude into the amniotic cavity from the fetal surface near the cord insertion. Calcification and necrosis are occasionally visible [10].

n sonography, the lesion

is well circumscribed and has echogenicity dif-

ferent from that of the rest of the placental tissue.

Large tumors can be of variable shapes, divided

by fibrous septa, and often protrude into the

amniotic cavity from the fetal surface near the

cord insertion

n sonography, the lesion

is well circumscribed and has echogenicity dif-

ferent from that of the rest of the placental tissue.

Large tumors can be of variable shapes, divided

by fibrous septa, and often protrude into the

amniotic cavity from the fetal surface near the

cord insertion

n sonography, the lesion

is well circumscribed and has echogenicity dif-

ferent from that of the rest of the placental tissue. 
Large tumors can be of variable shapes, divided

by fibrous septa, and often protrude into the

amniotic cavity from the fetal surface near the

cord insertion

n sonography, the lesion

is well circumscribed and has echogenicity dif-

ferent from that of the rest of the placental tissue.

Large tumors can be of variable shapes, divided

by fibrous septa, and often protrude into the

amniotic cavity from the fetal surface near the

cord insertion In the present case, we used Doppler ultrasound to monitor fetal wellbeing and circulation; however, despite the presence of the large chorioangioma, there were no signs of anemia or cardiac failure. Macroscopically, chorioangiomas are well-circumscribed tumors. On cut section, they are usually fleshy, congested, and red to tan. We occasionally note the presence of myxoid, fibroma-like or degenerative changes. Placental chorioangiomas are often found on the fetal surface of the placenta with a few cases reported on the maternal surface as well [6].

The majority of placental chorioangiomas are small measuring less than $5 \mathrm{~cm}$ in diameter and are located entirely in the placental parenchyma; that is why we can be easily miss them if the placenta is not systematically sliced after delivery [11]. In the present case, the tumor measured $8.3 \times 4.9 \mathrm{~cm}$ and was located on the fetal surface near the umbilical cord insertion with focal cystic change. The definitive diagnosis of placental chorioangioma relies on histopathological examination. Histologically, chorioangioma is a benign tumor proliferation of vessels accompanying connective tissue and an abundant stromal component. The proportion of vascular and stromal components are variable, depending upon the dominant histologic type. The vascular component may comprise either capillaries or sinusoids. Based on histology, the tumor can be classified as capillary, cavernous, endotheliomatous, fibrosing, and fibromatous. Such differentiation is not of clinical concern, since the prognosis depends mainly upon the size of the tumor. In the current case, the tumor was of the capillary type [10-11]. There is a rare variant of chorioangioma: "atypical cellular chorioangioma" characterized by high mitotic activity, cellularity and abnormal nuclei with proliferating malignant trophoblast interspersed among proliferating capillaries with large areas of necrosis [12]. The immunohistochemical study shows a positive immunostaining of tumor cells for CD31, CD 34, factor VIII, GLUT 1, and cytokeratin 18. The differential diagnosis of placental chorioangioma includes chorangiosis and chorangiomatosis. Prognostic factors that influence the outcome of placental chorioangioma are vascularity and location of the tumor. Increased vascularity leads to greater shunting of blood to the physiologic dead space of the tumor, weaning the fetus of a significant amount of nutrient and air exchange and perhaps manifesting as intrauterine growth restriction and fetal demise. Likewise, location is also critical in deciding the pregnancy outcome, as, in certain reported cases, chorioangiomas as small as $2 \mathrm{~cm}$ located at the outer edge of the placenta have been associated with complications [8].

Management of chorioangioma depends on its degree of severity. For mild to moderate types, the treatment is conservative as it was the case for our patient. For severe cases, there are several management modalities including in-utero endoscopic devascularization and prenatal treatment by ultrasound guided interstitial laser therapy. In case of fetal anemia, in-utero blood transfusion can be done with good outcome. In case of polyhydramnios, maternal indomethacin therapy or amniocentesis is useful in management. If complications appear late in pregnancy delivery is the option of management. [13].

In summary, placental chorioangioma is associated with an increased risk of complications influencing the outcome of pregnancy. Despite the existence of uncomplicated cases, close monitoring and follow up of the 
patients by serial ultrasound, surveillance by Doppler, and fetal echocardiography is highly recommended for these patients. Careful examination of the placenta, timely antenatal diagnosis, and early intervention are of paramount importance, to prevent associated morbidity and mortality to both the fetus and the mother. In the current case, except for prematurity, there were no clinically significant complications due to the giant placental chorioangioma measuring $8 \mathrm{~cm}$ in diameter.

\section{CONFLICT OF INTEREST STATEMENT}

None declared.

\section{AUTHORS' CONTRIBUTIONS:}

Dr Faten LIMAIEM prepared, organized, wrote, and edited all aspects of the manuscript. She performed the gross and microscopic pathologic evaluation of the pathology specimen. She prepared all of the histology figures in the manuscript. She read, edited, and approved the final version of the manuscript.

All authors should have made substantial contributions to the manuscript.

Dr Khalil SAFFAR and ANISSA BEN AMOR participated in

The conception and design of the study,

The acquisition of data, analysis and interpretation of the data,

Pr Saadia Bouraoui and Pr Amel Triki participated in

The drafting of the article and revising it critically for important intellectual content,

All authors participated in the

Final approval of the manuscript before its submission

\section{ETHICAL APPROVAL}

All procedures performed were in accordance with the ethical standards. The examination was made in accordance with the approved principles.

\section{ACKNOWLEDGEMENT STATEMENT}

I would like to offer my special thanks to Mrs Saïda Jerbi who prepared the microscopic slides. Published with written consent of the patient.

\section{DATA AVAILABILITY}

In accordance with the DFG Guidelines on the Handling of Research Data, we will make all data available upon request.

\section{REFERENCES}

[1] Dao AH, Rogers W, Wong SW. Chorangiomas of the placenta: Report of two cases with Ultrasound study in one. Obstet Gynecol. 1981;57(6):46-9.

[2] Saxena A, Faujdar M, Kaur A, Gupta S. Large Placental Chorangioma with an Unusual Uneventful Course. Journal of Gynecologic Surgery. 2017; 33 (1): 30-33.

[3]. Kirkpatrick A, Podberesky DJ, Gray AE, McDermott JH. Placental chorangioma. Radiographics. 2007;27:1187.

[4]. Esen UI, Orife SU, Pollard K. Placental chorangioma: A case report and literature review. Br J Clin Pract. 1997; 51:181.

[5]. Guschmann M, Henrich W, Entezami M, Dudenhausen JW. Chorioangioma - new insights into a wellknown problem: I. Results of a clinical and morphological study of 136 cases. J Perinat Med. 2003;31:163. 
[6]. Khanam R, Ghosh PK, Jahan F, Rahman S. Chorangioma. J Med Case Reports. 2013;14:185-6.

[7]. Nanda SS, Dash S, Huria A. Placental chorioangioma and preterm labour: A case Report. Sch J Appl Med Sci. 2013;15:400-2.

[8]. Kataria N, Singh A, Bedi PK. Giant Placental Chorangioma: A Rare Case Report. J Clin Diagn Res. 2016;10:ED 03-4.

[9]. Sabhikhi AK, Chaudhary MC, Singh D, Raja LN. Chorangioma of the placenta with Hydrops Fetalis. Indian Paediatr. 1996;33:520-1.

[10]. Zalel Y, Weisz B, Gamzu R, Schiff E, Shalmon B, Achiron R. Chorioangiomas of the placenta: Sonographic and Doppler flow characteristics. J Ultrasound Med. 2002;21:909-13.

[11] Duro EA, Moussou I. Placental chorioangioma as the cause of non-immunologic hydrops fetalis: A case report. Iran J Pediatr. 2011;21:113.

[12]. Majlessi HF, Wagner KM, Brooks JJ. Atypical cellular chorangioma of the placenta. Int J Gynecol Pathol. 1983;1:403.

[13]. Das R, Subedi N, Gurung G. Chorioangioma of Placenta. J Nepal Med Assoc. 2017; 56: 472-4.

\section{FIGURE LEGENDS:}

\section{Multipanel figure 1:}

Figure 1 A : Ultrasonography showing a well-defined heterogeneous and hypoechoic space-occupying placental lesion measuring $8.3 \times 4.9 \mathrm{~cm}$ and bulging into the amniotic cavity at the site of umbilical cord insertion. Figure 1 B: Color Doppler imaging showing a heterogeneous echogenic large lobular mass measuring approximately $8 \times 4.9 \mathrm{~cm}$ and increased blood flow within the tumor.Figures $\mathbf{1} \mathbf{C}+\mathbf{1}$ D: Macroscopic view of the placental chorioangioma. On cut section, there is a well-defined lobular mass on the fetal surface measuring $8 \times 4.9 \mathrm{~cm}$ and located near the insertion of the umbilical cord. On serial sections, the cut surface of the mass was solid whitish with few reddish and micro cystic areas. The rest of the placenta, membranes, and umbilical cord were unremarkable.

Multipanel figure 2:

Figure 2 A Microscopic examination of the placental mass showing a well-demarcated lesion composed of numerous capillary-sized vascular channels within a fibrous matrix. ( Hematoxylin and eosin, magnification $\times$ 40), Figure 2 B: Variable sized capillaries within a fibrous matrix ( Hematoxylin and eosin, magnification $\times$ 100). Figure 2 C: Capillaries are lined by endothelial cells devoid of atypia (Hematoxylin and eosin, magnification $\times 400$ ).

Figure 2 D: Immunohistochemical study showing strong positive immunostaining of the endothelial cells with the CD34 antibody, (Immunohistochemistry, magnification $\times 400$ ). 

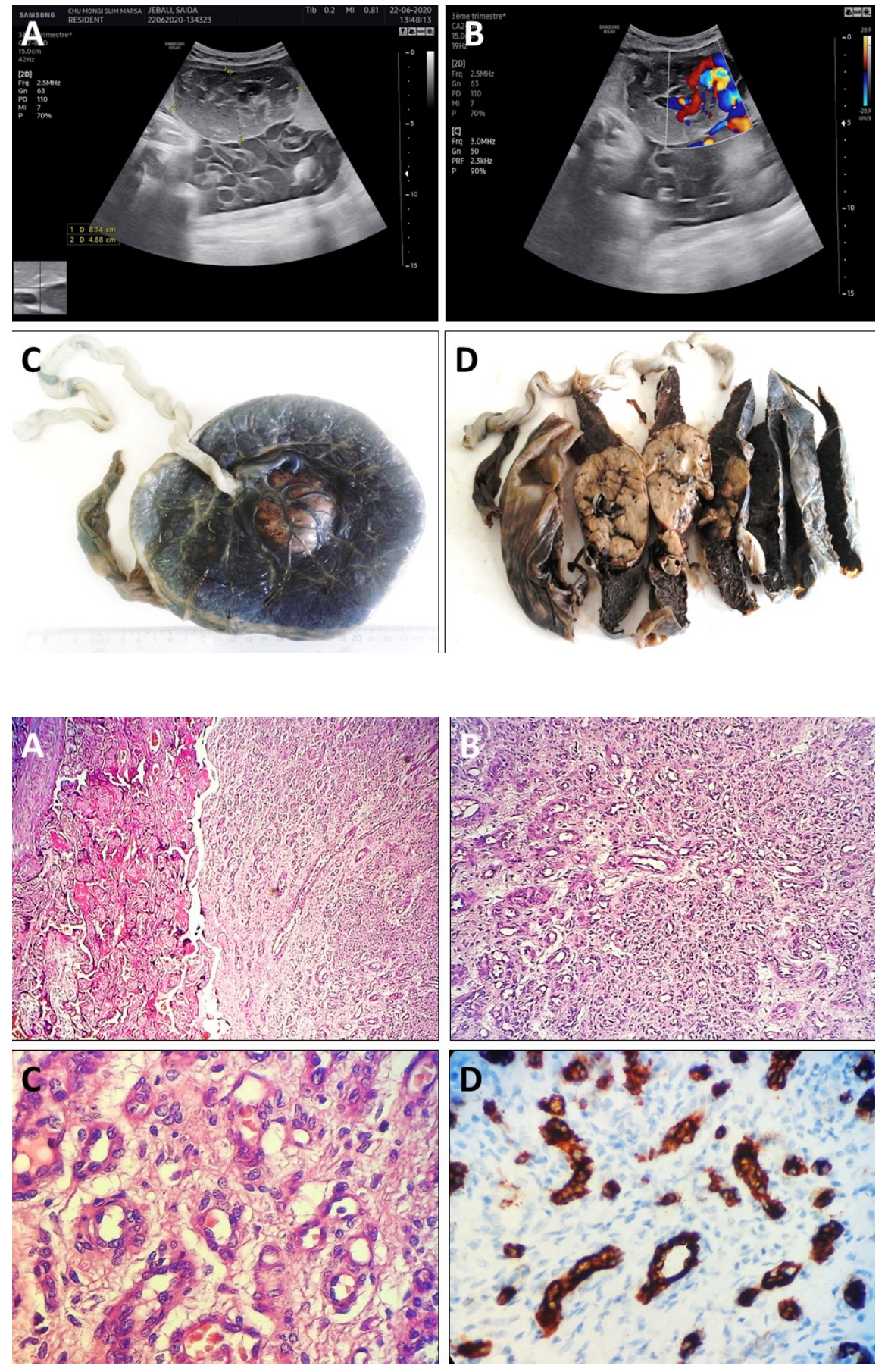